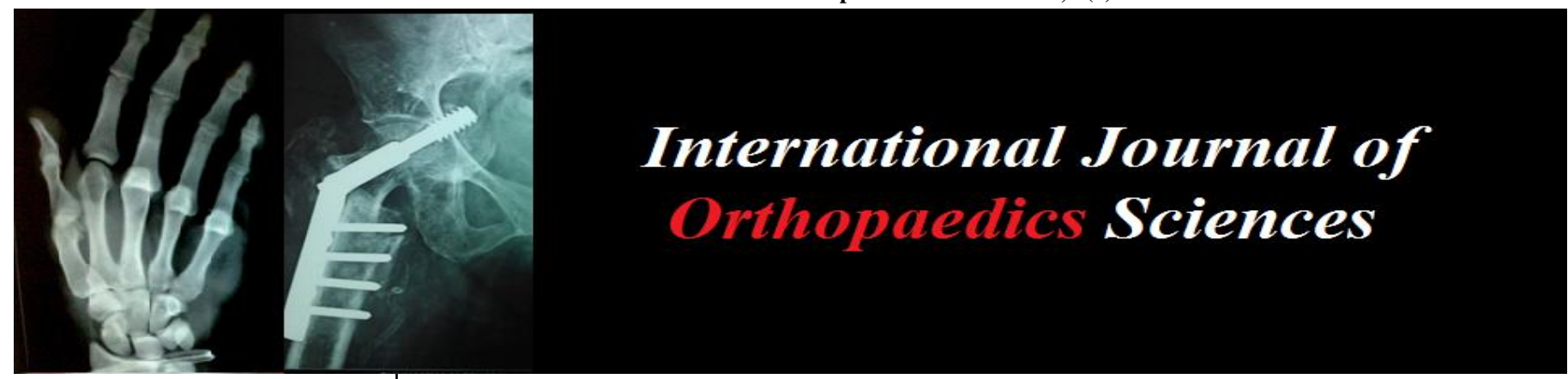

E-ISSN: 2395-1958

P-ISSN: 2706-6630

IJOS 2020; 6(4): 221-224

(C) 2020 IJOS

www.orthopaper.com

Received: 10-07-2020

Accepted: 13-08-2020

Jibran Bashir

DNB Senior Resident,

Department of Orthopaedics,

Asian Institute of Medical

Sciences Faridabad, Haryana, India

Noor Arshad

Assistant Professor, Departmen of Orthopaedics, Index Medical

College, Indore, Madhya

Pradesh, India

\section{Anshu Kumar}

PG Resident, Department of Orthopaedics, Asian Institute of Medical Sciences, Faridabad,

Haryana, India
Corresponding Author:

Jibran Bashir

DNB Senior Resident,

Department of Orthopaedics,

Asian Institute of Medical

Sciences Faridabad, Haryana,

India

\section{Treatment of fractures of lateral end of clavicle with open reduction using clavicle hook plate}

\author{
Jibran Bashir, Noor Arshad and Anshu Kumar
}

DOI: https://doi.org/10.22271/ortho.2020.v6.i4d.2343

\section{Abstract}

Background: Fracture of lateral end clavicle constitutes merely $15 \%$ of clavicle fracture, only a third of these fractures are displaced. No solo treatment method has been hailed as the most favored technique to deal with the fracture lateral end clavicle, yielding consistently good union, with least complications.

Objective: This early study attempts to assess the role of Clavicle Hook Plate, in the dealing lateral end clavicle fractures, whether it promises to be the most preferred technique.

Material and Methods: To assess the results and long term effects in use of this plate we performed a retrospective analysis with a mean follow up of 24 months (2 years) of 20 patients with acute displaced lateral clavicle fractures, fixed with the clavicle hook plate.

Results: Our short term results in all patients were first-class to excellent. None underwent non- union. Impingement symptoms were detected in 4 patients, 1 patient had skin/soft tissue issues and 1 had infection, warranting early implant removal. patients were re-evaluated at a mean follow-up period of 2 years.

Conclusions: Clavicle hook plate is a reasonably good key treatment choice in fixing the acute displaced lateral end clavicle fractures. Proper selection of patients with good skin conditions and infection control are essential.

Keywords: Treatment, fractures, lateral, clavicle, hook

\section{Introduction}

Fracture of lateral end of clavicle is $15 \%$ of the total clavicle fracture, although conservative treatment of clavicle fractures has been very well acknowledged by the society but lately patients are turning more demanding shifting the management towards operative side.

Usually 1/3rd of these fractures get displaced (Type 2 Neer's or Type 3B1 Edinburgh) ${ }^{[1]}$. The clavicle hook plating has emerged as a revolutionary surgical option for such fractures $[2,3,4,5,6$, $7,8,9,10,11]$. It has been amply proven by time that union has never been a bothersome issue in these fractures, but even a decade ago it was convincingly shown in a study that long term complication of the clavicle fracture can occur like acromio -clavicular joint problems ${ }^{[11]}$.

To assess the role of hook plate in lateral end clavicle fractures, we studied \& followed up the selected patients for an average period of 24 months. 20 patients presented in our department OPD and Emergency, with acute lateral clavicle fractures, who had displacements past the limits of acceptability, hence were treated with the open reduction and clavicle hook plating.

\section{Material and Methods}

20 consecutive patients were chosen who had displaced fractures, in a tertiary care hospital who had been operated for hook plate were retrospectively evaluated. The hospital caters both urban and of rural population in. $60 \%$ of the population includes farmers and semi-skilled labroures and workers. Majority of patients are high demanding as far as range of movements and heavy weight lifting ability is concerned. The cases were followed up for 2 years by the same surgical team which operated upon the individual patient, to eliminate any bias. The movements (active \& passive both) were started on 7th post-operative day. Union was assessed from time to time after 3 and 8 weeks, Following which patients were advised resumption of normal daily activities, except heavy weight lifting for total 3 months or radiological sound union. 
The case history and examination sheets were analysed and post-operative $x$-rays were re-analysed. Following the initial evaluation, we examined the patient in OPD. Range of shoulder movements were carefully evaluated as passive and active function separately to be included with subjective perceptions for DASH scoring.

The Hook-Plate: This plate is a $3.5 \mathrm{~mm}$ pre-contoured stainless steel /titanium, dynamic compression, locking/ non locking plate, with a wider anterolateral end and a lateral extension with a step low, into a hook which can be slided below the acromion. The objective being that the plate itself rests along the superior surface of the fractured clavicle fragments while the hook anchors below the acromion. These plates are available with 6 or 8 holes and the hook depth being $15 \mathrm{~mm}$.

Technique: The patients were operated in supine position, with a bolster underneath the operable shoulder under general anaesthesia. The arm is kept on the affected side, free to move. A curved skin incision, placed over the fracture was used in all the cases. Skin flaps were elevated, taking care to keep the flap as thick as possible to ensure its viability. The fracture fragments were dissected with minimum soft tissue periosteal elevation. The fracture fragments were reduced carefully and were temporarily fixed with smooth K-wires. Under image intensifier AC joint was located. The soft tissue dorsal to the AC joint was slit just enough insertion of the hook of the plate. First the hook the plate hook depth is manoeuvred below the acromion. The shaft of the plate was placed on the superior aspect of the clavicle and fixed with a $\mathrm{k}$-wire, the reduction of fragments were confirmed by rotating image intensifier to get oblique views of fracture The well pre-contoured plate aligns well with the clavicle, but was bent if need be. The plate was fixed with locking screws. Adequate precaution was taken to avoid injury to the underlying neurovascular bundle. The wound closed without tension, with cosmetic subcutaneous sutures, to hold over the plate.

\section{Results}

All twenty patients with a displaced lateral end clavicle fracture, were operated in supine position with open reduction and internal fixation by the clavicle hook plate. Mean age was 40 years (range 20-60) male to female ratio was 16:4. All patients had an Edinburgh Type 3B1/ Neer Type II fracture. Mean time to operation was 3 days and the mean operating time was 60 minutes 30 to 90 minutes, from start of incision to closure. All patients were discharged on the second or third day of surgery depending on the conditoin of the wound on first dressing and pain status of patient according to VAS score. All the patients were followed up for average 2 years with first visit to the OPD a week after the surgery followed by 3 weeks, 6 weeks, 9 weeks, 3 months, 9 months, 18 months and so on.

Our short term results in all patients were first-class to excellent. None underwent non- union. Impingement symptoms were detected in 4 patients, 1 patient had skin/soft tissue issues and 1 had infection, warranting early implant removal. Patients were re-evaluated at a mean follow-up period of 2 years.

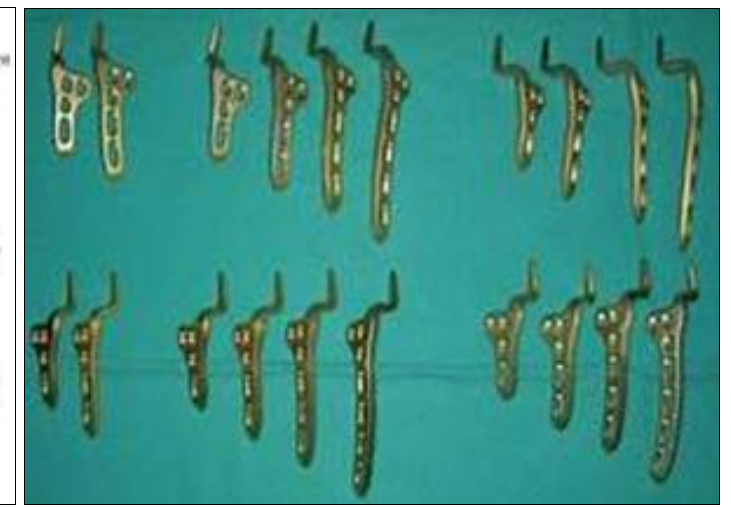

Fig 4: Clavicle Hook Plates

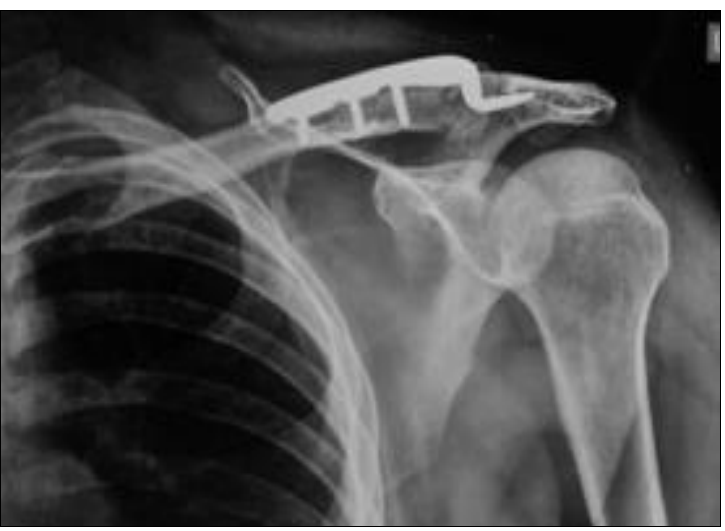

Fig 4: Post op follow up after lateral plate fixation

Fig 3: Fracture Lateral End Clavicle (Neer II) 


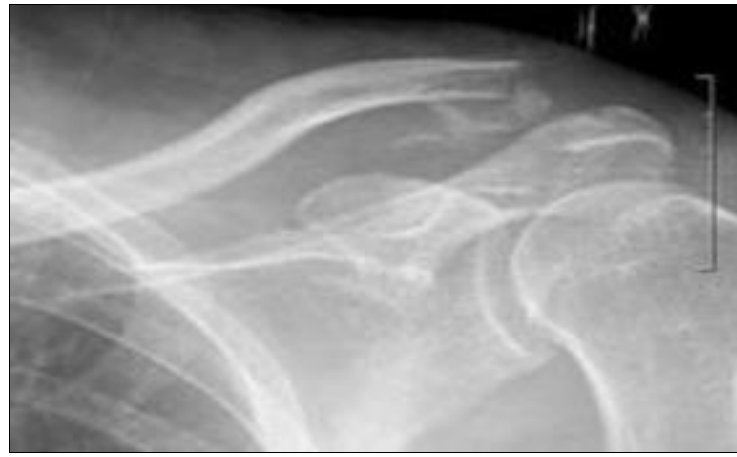

Fig 5: Fracture lateral end Clavicle Neer II

\section{Discussion}

In our study, there were 20 patients, out of which 4 patients (20\%) were female and 16 patients $(80 \%)$ were male with male to female ratio is $16: 4$. If we divide the patients in age groups 6 patients $(30 \%)$ were between the age group of 31-40 years, 4 patients $(20 \%)$ were between the age group of 21-30 years, 4 patients $(20 \%)$ were between the age group of $41-50$ years and 2 patients $(10 \%)$ were between the age group of 51 60 years with the mean age of 40 years.

On comparing the patients on the basis of time between the injury and the operation, all the patients had duration between 0-5 days, with the meantime 2 days. The mean intra-operative time from incision to closure was 60 minutes.

We followed up the patients for an average time of 2 years and evaluated with the DASH score. The mean DASH score was 1.27. During follow up 1 patient reported skin incision irritation pain and 4 of these patients were diagnosed with impingement and this resolved shortly after plate removal the patients with impingement has symptoms of discomfort and pain between 70 and 130 degree of elevation (abduction in the plane of scapula).Impingement was confirmed by neer impingement test i.e., local injection of $2 \%$ lidocaine $2 \mathrm{ml}$, under the acromion, in sub-acromial space, bringing relief to the pain instantly.

One patient suffered infection, probably due to uncontrolled diabetes. This patient ultimately required implant removal, despite suitable intravenous antibiotics being injected after pus culture and sensitivity. The organism grown was staphylococcus aureus, though sensitive to regular antibiotics, couldn't be controlled until the plate was removed.

The single patient with skin irritation was probably due to incision just overlying the plate and screws. Locking screws that merge in the plate thickness do have an advantage. Despite all patients were advised to remove the plate after clinical and radiological consolidation. ur results were comparable with Flinkkila et al., ${ }^{[6]}$ he compared K-wire fixation to hook plating. Although the functional results were same, still they advised hook plates because of migration and infection in the former group. Lee et al. ${ }^{[5]}$ compared K-wiring with tension band wiring to hook plate fixation. Their results showed that the group with the hook plate had earlier regained of pre-injury activities. The K-wire fixation group had $30 \%$ complications mainly related to hardware failure.

Neer has described fracture lateral clavicle as an unstable clavicle fracture needing operative treatment because of increased incidence non-union and rate of delayed union. His explanation is by that the deforming forces around the fracture, and interposition between the fracture fragments, along with continuous motion atthe fracture ends $[22,24,25]$ contribute to the aforesaid prognosis.

The clavicle hook plate is a simple to use implant that

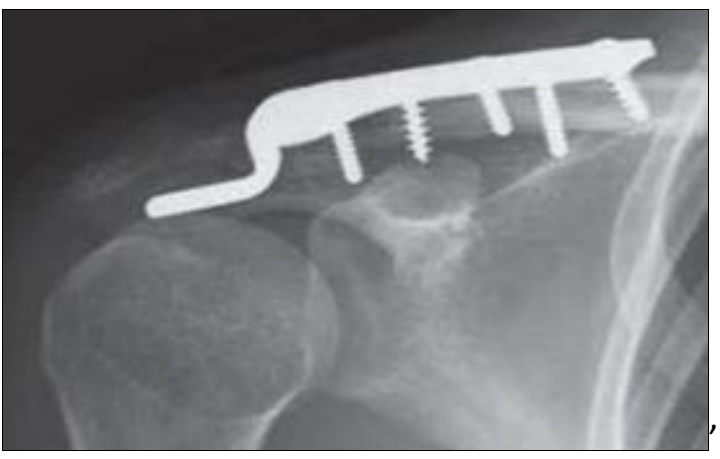

Fig 6: Post op Follow up after Lateral Plate fixation

withstands forces that are applied to the fracture fragments. By it's shape it keeps the lateral end of the clavicle aligned, thereby reducing the clavicle with the ligaments and minimizing movement at the fracture ends without interfering with rotation of the clavicle ${ }^{[12]}$.

The results published in several studies [2-11]. Show good results regarding bony union and in terms of shoulder function. Shoulder function is checked with the use of Constant-Murley \& DASH scores. The DASH score is below 5 and the Constant-Murley score comes around 90. Nonunion is seldom, below $10 \%$ which is comparable to our study.

\section{Conclusions}

Clavicle plate in our short study, has shown without a doubt tried and true necessary treatment decision in treating the severely displaced lateral end clavicle fractures. A strict convention of legitimate choice of patients, with great nearby skin conditions, dealing with all systemic ailments (obligated to bring about post-agent issues) are taken into consideration before going with the clavicular hook plate fixation.

\section{Reference}

1. Robinson CM: Fractures of the clavicle in the adult. Epidemiology and classification. J Bone Joint Surg Br 1998;80:476-484. 10.1302/0301-620X.80B3.8079.

2. Haidar SG, Krishnan KM, Deshmukh SC: Hook plate fixation for type II fractures of the lateral end of the clavicle. J Shoulder Elbow Surg 2006;15:419-423. 10.1016/j.jse.2005.11.012.

3. Renger RJ, Roukema GR, Reurings JC, Raams PM, Font J, Verleisdonk EJ: The clavicle hook plate for Neer type II lateral clavicle fractures. J Orthop Trauma 2009;23:570-574. 10.1097/BOT.0b013e318193d878.

4. Lee KW, Lee SK, Kim KJ, Kim YI, Kwon WC, Choy WS: Arthroscopic-assisted Locking Compression Plate clavicular hook fixation for unstable fractures of the lateral end of the clavicle: a prospective study. Int. Orthop 2009.

5. Lee YS, Lau MJ, Tseng YC, Chen WC, Kao HY, Wei JD: Comparison of the efficacy of hook plate versus tension band wire in the treatment of unstable fractures of the distal clavicle. Int. Orthop 2009;33:1401-1405. 10.1007/s00264-008-0696-7.

6. Flinkkila T, Ristiniemi J, Hyvonen P, Hamalainen M: Surgical treatment of unstable fractures of the distal clavicle: a comparative study of Kirschner wire and clavicular hook plate fixation. Acta Orthop Sc and 2002;73:50-53. 10.1080/000164702317281404.

7. Tambe AD, Motkur P, Qamar A, Drew S, Turner SM: Fractures of the distal third of the clavicle treated by 
hook plating. Int. Orthop 2006;30:7-10. 10.1007/s00264005-0019-1.

8. Meda PV, Machani B, Sinopidis C, Braithwaite I, Brownson P, Frostick SP: Clavicular hook plate for lateral end fractures:- a prospective study. Injury 2006;37:277-283. 10.1016/j.injury.2005.10.017.

9. Muramatsu K, Shigetomi M, Matsunaga T, Murata Y, Taguchi T: Use of the AO hook-plate for treatment of unstable fractures of the distal clavicle. Arch Orthop Trauma Surg 2007;127:191-194. 10.1007/s00402-0060284-5.

10. Bhangal KK, Evans SC, Gibbons E: Treatment of Displaced Lateral Clavicle Fractures with the AO Hook Plate. European Journal of Trauma 2006;5:468-470.

11. Flinkkila T, Ristiniemi J, Lakovaara M, Hyvonen $P$, Leppilahti J: Hook-plate fixation of unstable lateral clavicle fractures: a report on 63 patients. Acta Orthop 2006;77:644-649. 10.1080/17453670610012737.

12. Kiefer H, Claes L, Burri C, Holzwarth J: The stabilizing effect of various implants on the torn acromioclavicular joint. A biomechanical study. Arch Orthop Trauma Surg 1986;106:42-46. 10.1007/BF00435651.

13. Eberle C, Fodor P, Metzger U: [Hook plate (so-called Balser plate) or tension banding with the Bosworth screw in complete acromioclavicular dislocation and clavicular fracture]. Z Unfallchir Versicherungsmed 1992;85:134139.

14. Moneim MS, Balduini FC: Coracoid fracture as a complication of surgical treatment by coracoclavicular tape fixation. A case report. Clin Orthop Relat Res 1982,133-135.

15. Kona J, Bosse MJ, Staeheli JW, Rosseau RL: Type II distal clavicle fractures: a retrospective review of surgical treatment. J Orthop Trauma 1990;4:115-120. 10.1097/00005131-199004020-00002.

16. Kaipel M, Majewski M, Regazzoni P: Double-Plate Fixation in Lateral Clavicle Fractures-A New Strategy. J Trauma 2010.

17. Goldberg JA, Bruce WJ, Sonnabend DH, Walsh WR: Type 2 fractures of the distal clavicle: a new surgical technique. J Shoulder Elbow Surg 1997;6:380-382. 10.1016/S1058-2746(97)90006-9.

18. Jackson WF, Bayne G, Gregg-Smith SJ: Fractures of the lateral third of the clavicle: an anatomic approach to treatment. J Trauma 2006;61:222-225. 10.1097/01.ta.0000196804.23024.a3.

19. Mall JW, Jacobi CA, Philipp AW, Peter FJ: Surgical treatment of fractures of the distal clavicle with polydioxanone suture tension band wiring: an alternative osteosynthesis. J Orthop Sci 2002;7:535-537. $10.1007 / \mathrm{s} 007760200095$.

20. Yamaguchi H, Arakawa H, Kobayashi M: Results of the Bosworth method for unstable fractures of the distal

21. clavicle. Int. Orthop 1998;22:366-368. 10.1007/s002640050279.

22. Ballmer FT, Gerber C: Coracoclavicular screw fixation for unstable fractures of the distal clavicle. A report of five cases. J Bone Joint Surg. Br 1991;73:291-294.

23. Neer CS: Fracture of the distal clavicle with detachment of the coracoclavicular ligaments in adults. J Trauma 1963;3:99-110. 10.1097/00005373-196303000-00001.

24. Robinson CM, Cairns DA: Primary nonoperative treatment of displaced lateral fractures of the clavicle. $\mathrm{J}$ Bone Joint Surg. Am 2004;86-A:778-782.

25. Rokito AS, Zuckerman JD, Shaari JM, Eisenberg DP,
Cuomo F, Gallagher MA: A comparison of nonoperative and operative treatment of type II distal clavicle fractures. Bull Hosp Jt Dis 2002;61:32-39.

26. Neer CS: Fractures of the distal third of the clavicle. Clin Orthop Relat Res. 1968,58:43-50.

27. Nadarajah R, Mahaluxmivala J, Amin A, Goodier DW. Clavicular hook-plate: complications of retaining the implant. Injury 2005;36:681-683 31. Chandrasenan J, Badhe S, Cresswell T, Beer J. The Clavicular Hook Plate: Consequences in Three Cases. European Journal of Trauma and Emergency Surgery 2007;5:557-559. 32.

28. Kaipel M, Majewski M, Regazzoni $P$ Double-Plate 27. ElMaraghy AW, Devereaux MW, Ravichandiran K, Agur Fixation in Lateral Clavicle Fractures-A New Strategy. J AM morphometric assessment of the Trauma clavicle hook plate. Inj 2010. 